\title{
Temporary A-V sequential pacing using transluminal pacing electrodes
}

$A$ case is presented which describes the initiation of atrialvenuricular $(A-V)$ sequential pacing using atrial epicardial wires and an in-situ transtuminal ventricular pacing probe. A 68. year-old female with a permanent A-V sequential pacemaker was scheduled for elective aortocoronary bypass. Following sternotomy, pacing function was converted to ventricular pacing (VVI) with the use of electrocaurery. A Chandler $V$-pacing probe was introduced through a $P$ aceport ${ }^{*}$ (American Edwards) pulmonary artery catheter and with a paced increase in ventricular rate, the cardiac output increased from 2.8 to $3.2 \mathrm{~L} \cdot \mathrm{min}^{-1}$. At the conclusion of cardiopulmonary bypass the patient was in sinus rhythm al a rate of $67 \cdot \mathrm{min}^{-1}$ and was paced to a faster rate using bipolar atrial epicardial wires. The patient subsequently developed intermittent heart block so temporary A-V sequential pacing was established using atrial epicardia! wires and the in situ ventricular pacing probe. Pacing was achieved at routine generalor outpur settings of seven milliamps ( $\mathrm{MA}$ ) for boih atrium and ventricle and at an A-V interval of $0.120 \mathrm{sec}$. This resulted in an immediate increase in cardiac output from 3.3 to $4.1 \mathrm{~L} \cdot \mathrm{min}^{-1}$. The compatability of these wo pacing systems offers an increased margin of safety in cardiar surgery patients requiring atrial pacing, who are at risk for developing postopcrative heart block.

Key words

EQUIPMENT, HEART: temporary pacemaker; TECHNIQUES: A-V sequential pacing, transluminal pacing.

From the Department of Anesthesiology, Jefferson Medical College of Thomas Jefferson University, 111 South 11th Street, Philadelphia, Pennsylvania 19107.

Address correspondence to: Dr. McNulty.
Intraoperative placement of temporary wires has been recommended during cardiac surgical cases. ${ }^{1,2}$ Routine placement of atrial, ventricular or both atrial and ventricular pacing leads is practiced by many surgeons during open-heart surgery. The following case report describes the use of an in situ bipolar transluminal ventricular pacing probe in conjunction with bipolar epicardial atrial wires to establish $\mathrm{A}-\mathrm{V}$ sequential pacing in a patient with atrio-ventricular heart block following cardiopulmonary bypass.

\section{Case report}

The patient was a 68 -year-old, $80 \mathrm{~kg}$ female with triple vessel coronary artery disease and progressive angina, scheduled for elective coronary artery hypass surgery. The patient had a Medtronic model \#7005 A-V sequential pacemaker placed two months prior to admission, for high grade A-V block. It was decided that pulmonary artery pressure monitoring would be beneficial so a Paceport ${ }^{\text {(I) }}$ (American Edwards) pulmonary artery cathether was placed in the right internal jugular vein to allow for emergency ventricular pacing, if it became necessary. The Paceport ${ }^{\$}$ pulmonary artery catheter has a modified right ventricular port which accepts a separately packaged Chandler ${ }^{3}$ (American Edwards) transluminal ventricular pacing wire. The case proceeded uneventfully until shortly before atrial cannulation when use of the electrocautery converted the permanent pacemaker function from an A-V sequential rate of $75 \cdot \mathrm{min}^{-1}$ to ventricular pacing (VVI) at a rate of $60 \cdot \mathrm{min}^{-1}$. The haemodynamic response was a decrease in blood pressure from $116 /$ $70 \mathrm{mmHg}$ to $90 / 55 \mathrm{mmHg}$ and a decrease in cardiac output (CO) from 4.2 to $2.8 \mathrm{~L} \cdot \mathrm{min}^{-1}$. Temporary transvenous pacing to a rate of $80 \cdot \mathrm{min}^{-1}$ was instituted using the ventricular pacing probe thereby improving blood pressure to $98 / 58 \mathrm{mmHg}$ and $\mathrm{CO}$ to $3.2 \mathrm{~L} \cdot \mathrm{min}^{-1}$. Temporary pacing was discontinued during cardiopulmonary bypass (CPB) while four distal anastamoses and three proximal anastamoses were completed. Reprograming capability for the permanent pacemaker was not available. Immediately prior to weaning from CPB, the patient was in sinus rbythm at a rate of 67 beats $\cdot \mathrm{min}^{-1}$. Bipolar atrial 
epicardial wires were placed and the heart was paced to a rate of $80 \cdot \mathrm{min}^{-1}$. Initial haemodynamic stability was disrupted 15 minutes after discontinuation of CPB by the development of intermittent heart block during which the patient's systolic BP decreased from 100 to $80 \mathrm{mmHg}$ Temporary A-V sequential pacing was established using the epicardial leads on the atrium and the endocardial leads of the ventricular pacing probe. Satisfactory pacing was achieved using a Medronic ${ }^{\text {(3) }} 5330 \mathrm{~A}-\mathrm{V}$ sequential pulse generator at output settings of $7 \mathrm{~mA}$ for both atrium and ventricle and at an $A-V$ interval of $0.12 \mathrm{sec}$. There was immediate improvement in that systolic BP increased to $106 \mathrm{mmHg}$ while $\mathrm{CO}$ increased from 3.3 to 4.1 $\mathrm{L} \cdot \mathrm{min}^{-1}$. The patient's condition was stable throughout the remainder of the case. Temporary A-V sequential pacing was continued until the patient's permanent pacemaker could be reprogrammed in the intensive care unit.

\section{Discussion}

This case report demonstrates a variety of applications for temporary pacing in the cardiac surgical patient. The preoperative plan to utilize the Paceport pulmonary artery catheter in this patient was the result of several considerations. There was a concern that thete could be a lead wire disruption during the placement of the catheter even though the pacemaker had been in place for two months. Wynands reported that lead wire disruption occurred during the simple manoeuvre of hyperextension of the arm in a patient with recent pacemaker implantation. ${ }^{3}$ The second consideration involved the possible conversion of the programmable pacemaker with electrocautery. Although a programmer was available on the day of surgery it was unlikely that reprogramming would be possible at the moment needed. Therefore, the theoretic loss of ventricular capture and/or a decreased cardiac output resulting from a change in pacemaker function led us to utilize a modified pulmonary artery catheter to allow for emergency ventricular pacing.

When electrocautery caused permanent pacemaker function to convert from an $A-V$ sequential to ventricular mode, cardiac output decreased. Loss of properly timed atrial contraction may result in a 15-25 per cent decrease in ventricular preload ${ }^{4}$ In attempting to compensate for the decrease in cardiac output, the paced ventricular heart rate was increased using a bipolar transluminal pacing probe. Although this manoeuvre proved effective in this patient, there is evidence that increasing the ventricular rate may actually decrease $C O{ }^{5}$ Endocardial pacing was selected instead of epicardial pacing, first, because the pacing probe was more readily available and second, to avoid having epicardial wires in the field during vein graft anastamosis.
The most common application of temporary pacing in cardiac surgery remains to be the placement of epicardial pacing wires prior to discontinuation of $\mathrm{CPB}$ or prior to closure of the chest. There are advantages and disadvantages to be considered for the various pacing systems, frequently placed as a safeguard to treat postoperative rhythm disturbances. Ventricular pacing offers some protection from the sudden development of bradyarrhythmias; however, the decrease in cardiac output and mean arterial pressure resulting from loss of effective atrial contraction may be unacceptable in some patients. The use of atrial pacing may produce a greater improvement in haemodynamics than ventricular pacing alone. ${ }^{6}$ One of the concerns with the use of atrial pacing is that there is no therapeutic benefit in the patient who develops complete heart block postoperatively. Use of both atrial and vcntricular wires increased cardiac output 34 per cent compared to ventricular pacing alone and eight per cent compared to atrial pacing. ${ }^{7}$ However, the subsequent removal of multiple sets of epicardial wires involves a certain amount of patient discomfort and has been associated with haemothorax, ${ }^{8}$ pericardial tamponade, ${ }^{9,10}$ and arrbythmias."

There is evidence of equivalent effieacy and complication rate comparing permanent epicardial vs endocardial pacing. ${ }^{12}$ The use of epicardial wires as a potential support system necessitates their placement in every patient considered at risk. The advantage of the transluminal pacing system is that the ventricular pacing probe would only be introduced when needed. Experience with transluminal pacing suggests successful capture in 96 per cent of attempts in cardiac surgery patients. ${ }^{13}$ Failure to achieve successful placement of pacing electrodes may result from primary failure to properly place the pulmonary artery catheter due to asystole, small heart, or enlarged right atrium. Placement of the pacing probe in patients with normal sinus thythm may be associated with the development ventricular arrythmias. There is also a theoretic possibility of right ventricular perforation, pericardial tamponade or septal perforation with the use of an endacardial pacemaker although none of these complications has been reported with the Chandler ${ }^{2} \mathrm{~V}$-pacing probe.

In conclusion, the ability to establish $A-V$ sequentia pacing utilizing transluminal ventricular pacing electrodes increases the therapeutic benefit in patients with atrial epicardial leads who develop delayed onset of heart block following cardiopulmonary bypass. The reliability of the transluminal pacing catheter may also serve as an excellent backup in cardiac surgical cases where only atrial epicardial wires are routinely employed. 


\section{References}

1 Hodam RP. Starr A. Temporary post-operative epicardial pacing electrodes. Their value and management after open heart surgery. Ann Thorac Surg 1969; 8: 506-10.

2 Waldo AL, MacLean WA, Cooper TB et al. Use of temporarily placed epicardial atrial electrodes for the diagnosis and treatment of cardiac arrythmias following openheart surgery. J Thorac Cardiovasc Surg 1978; 76: 500-5.

3 Wynands JE. Anesthesia for patients with heart block and artificial cardiac pacemakers. Anesth Analg 1976; 55 : 626-32.

4 Zaiden JR. Pacemakers. In: Kaplan JA (Ed). Cardiac Anesthesia I. New York, Grune and Stratton 1979; 347-67.

5 Benchimol A, Ellis JG. Dimond EG. Hemodynamic consequences of atrial and ventricular pacing in patients with normal and abnormal hearts. Am J Med 1965; 39: 911-22

6 Raichlen JS, Campbell FW, Edie RN et al. The effect of the site of placement of temporary epicardial pacemakers on ventricular function in patients undergoing cardiac surgery. Circulation 1984; 70 (Suppl 1): 1-118.

7 Hartzler GO, Maloney JD. Curtis JJ, Barnhorst DA. Hemodynamic benefits of atrioventricular sequential pacing after cardiac surgery. Am J Cardiol 1977; 40: 232-6.

8 Ragaza EP, Low HB, Shapiro RL, Pericardial effusion with resultant right hemothorax after removal of epicardial pacing wires. I Thorac Cardiovase Surg 1973; 66: 814-6.

9 Baldwin BJ, Dorney $E R$. Acute cardiac tamponade following the removal of temporary epicardial pacemaker wires after open heart surgery. Am J Med Sci 1971; 261: 241-3.

10 Hoidal $C R$. Pcricardial tamponade after removal of an epicardial pacemaker wire. Crit Care Med 1986; 14: 305-6.

11 Harjula A, Jarvinen A, Mantila $S$ et al. Rcmoval of monofilamental and multifilamental temporary pacing leads following open heart surgery. Occurence of arrythmias. Pace 1985; 8: 607-10.

12 Mansour KA, Dorney ER, Tyras DH, Hascher CR. Cardiac pacemakers: comparing epicardial and pervenous pacing. Geriatrics 1973; 28: 151-5.

13 Mora CT, Seltzer JL, McNulty SE. Evaluation of a new design pulmonary artery catheter for intraoperative ventricular pacing. J Cardiothorac Ancsth (In Press).

\section{Résumé}

Un cas est présenté décrivant l'initianion d' un pacing séquentie auriculo-ventriculaire $(A-V)$ utilisant des électrodes auriculaires épicardiques et un probe in-situ pour pacing transluminai ventriculaire. Une femme agée de 68 ans porteuse d'un pacemaker $A-V$ séquentiel était cédulée pour un poniage aonto-coronarien électif. Après la sternotomie, le pacemaker fur converti en pacing ventriculaire (VWI) tors de l'utilisation de l'électrocautère. Un probe de pacing ventriculaire Chandier V-pacing a été introduit à travers le Paceport (American Edwards) du cathéter de l'artère pulmonaire et le rythme fut augntenté pour augmenter le débit cardiaque de 2.8 à 3.2 $L \cdot \mathrm{min}^{-1}$. A la fin de la circulation extra corporelle la patiente était en rythme sinusal à 67 et fut entrainée plus rapidement par le pace utilisant les úlectrodes bipolaires épicardiques auricutaires. La patiente par la suite développa un bloc intermistemt et un pacing séquentiel A-V temporaire utilisant des électrodes auriculaires épicardiques et l'electrode ventriculaire in siru. L'entraînement électrique fut établi avec un génêrateur habituel fixé à sept miliampères pour l' oreillette et le ventricule et à un interval $A-V$ de $0.120 \mathrm{sec}$. Ceci entraina une augmentation immédiate da débit cardiaque de 3.3 à $4.1 \mathrm{~L} \cdot \mathrm{min}^{-1}$, Lo compatibilité de ces deux systèmes de pacing offre une plus grande marge de sécurité chez les patients devant subir une chirurgie cardiaque requérant une stimulation de l'oreillette. 